Article

\title{
Hierarchical PtIn/Mg(Al)O Derived from Reconstructed PtIn-hydrotalcite-like Compounds for Highly Efficient Propane Dehydrogenation
}

\author{
Jiaxin Li, Ming Zhang, Zhen Song, Shuo Liu, Jiameng Wang and Lihong Zhang * \\ Department of Catalysis Science and Technology and Tianjin Key Laboratory of Applied Catalysis Science \& \\ Technology, School of Chemical Engineering and Technology, Tianjin University, Tianjin 300350, China; \\ xgclone@163.com (J.L.); minne_zhang@hotmail.com (M.Z.); songzhens12345@163.com (Z.S.); \\ shuoecho@outlook.com (S.L.); wangjiameng0216@163.com (J.W.) \\ * Correspondence: zlh_224@163.com or zlh_224@tju.edu.cn
}

Received: 8 August 2019; Accepted: 9 September 2019; Published: 12 September 2019

\begin{abstract}
The challenges facing propane dehydrogenation are to solve the Pt sintering and carbon deposition. This paper provides a new way to disperse and stabilize Pt species and resist carbon deposition. Highly dispersed Pt species were topologically transformed from reconstructed PtIn-hydrotalcite-like precursors in a flower-like hierarchical microstructure. The lattice confinement of reconstructed hydrotalcite-like precursor is in favor of stabilizing the highly dispersed Pt species, and the hierarchical microstructure is an important factor to prolong its lifetime by enhancing tolerance to carbon deposition. In propane dehydrogenation, the propene selectivity decreases in the sequences of catalyst in flower-like $>$ single-plate $>$ block mass with small, flakeys. A propene selectivity of $>97 \%$ with a conversion of $48 \%$ at $600{ }^{\circ} \mathrm{C}$ has been achieved over a flower-like PtIn/Mg(Al)O catalyst. Additionally, no visible Pt sintering can even be observed on this catalyst after a reaction time of $190 \mathrm{~h}$. This strategy provides an effective and feasible alternative for the facile preparation of highly dispersed metal catalysts.
\end{abstract}

Keywords: propane dehydrogenation; hierarchical microstructure; reconstruction; high selectivity; excellent durability

\section{Introduction}

Industrially, propene is a vital chemical material with a huge demand [1,2]. Catalytic propane dehydrogenation $(\mathrm{PDH})$ is considered an efficient technique to obtain propene [3,4]. In this process, catalyst $\mathrm{Pt} / \mathrm{Al}_{2} \mathrm{O}_{3}$ is widely used [5,6].

However, there are several open issues for this Pt-based catalyst under reaction conditions $[3,7,8]$, such as Pt sintering, carbon deposition and propane cracking. Extensive research efforts have been made to inhibit deactivation and improve propene selectivity of Pt-based catalysts by doping promoters of Sn [9,10], In [11,12], Ga [13,14] and Cu [15] to form bimetallic catalysts. For example, Pt-In [16] and $\mathrm{Pt}-\mathrm{Ga}[17,18]$ bimetallic nanoparticles (NPs) supported on calcined hydrotalcites (HT) show higher activity and selectivity in $\mathrm{PDH}$, which has been attributed to the increased Pt dispersion and electron transfer from In or $\mathrm{Ga}$ to $\mathrm{Pt}[11,18]$. Besides promoters, another method is to modify $\mathrm{Al}_{2} \mathrm{O}_{3}$ support with $\mathrm{ZnO}$ [19], $\mathrm{La}_{2} \mathrm{O}_{3}$ [20] or $\mathrm{TiO}_{2}$ [21] or replace $\mathrm{Al}_{2} \mathrm{O}_{3}$ support with $\mathrm{ZnAl}_{2} \mathrm{O}_{4}$ [22], ZSM-5 [23] or $\mathrm{Mg}(\mathrm{Al}) \mathrm{O}$ oxide [8,24]. Additionally, it has been verified that the single Pt atom sites on $\mathrm{Pt}-\mathrm{Sn} / \gamma-\mathrm{Al}_{2} \mathrm{O}_{3}$ with a "sandwich structure" are more favorable for PDH reaction than Pt ensembles [25,26]. Gong et al. [15] also reported that the $\mathrm{PtCu}$ single atom alloys can enhance the propane conversion and propene selectivity simultaneously in PDH.

Whether as promoters or supports, an important aim of using them is to obtain highly and stably dispersed Pt-based catalysts so that improving PDH performance. However, it is still difficult to 
break through these challenges for PDH reactions [27], and the exact Pt-M-support relationship is still unclear. Therefore, it is extremely necessary to find more efficient methods to solve the problems mentioned above.

In fact, the hierarchical morphology and porous structure play important roles in many heterogeneous catalytic reactions. However, the effect of hierarchical microstructure is seldom reported.

Additionally, calcined HT-like compounds are regarded as a good way to obtained supported metal catalysts with high surface area and atomic-scale uniform distribution of metal species due to the topotactic transformation [28]. These features, the changeable composition and the acid-base property make it is possible to improve PDH performance by optimizing Pt-based catalysts [8,24,29].

However, the most of HT-like compounds are prepared by co-precipitation method; as a result, the morphologies of as-synthetized products are usually low crystalline NPs consisting of a great number of small and thick plates [3,8]. That must be detrimental to fully utilizing the active metal species in bulk. Fortunately, the calcined HT can be reconstructed due to the memory effect of HT. During the process, some metal ions have the chance to be introduced into the layer of reconstructed HT $[30,31]$. The lattice-confined metal species can be converted into highly dispersed metal NPs and even single metal atom sites.

Given that the small Pt NPs and hierarchical microstructure may provide more stable and easily accessible active sites for $\mathrm{PDH}$ reaction, a promising design for obtaining the desired size of active $\mathrm{Pt}$ and hierarchical pore morphology was proposed. In this paper, $\mathrm{PtIn} / \mathrm{Mg}(\mathrm{Al}) \mathrm{O}$ catalyst in a flower-like nanosheet array (PtInHT-FR) was fabricated by reduction-followed by calcination of the flower-like PtIn-HT precursor (PtInHT-F) with a hierarchical microstructure, which produced from a sodium dodecyl sulfate-assisted hydrothermal synthesis, followed by thermal decomposition and structural reconstruction. Although there is no an additional support for this catalyst with low specific surface area, a stable and excellent propene selectivity of $>97 \%$ and a high conversion of $48 \%$ still can be achieved at $600^{\circ} \mathrm{C}$. As contrasting samples, the single-plate (PtInHT-PR) and block mass (PtInHT-MR) $\mathrm{PtIn} / \mathrm{Mg}(\mathrm{Al}) \mathrm{O}$ catalysts were derived from the corresponding high crystalline single-plate HT (PtInHT-P) and low crystalline block mass HT (PtInHT-M) with small, flakeys, which were synthesized by the hydrothermal synthesis and co-precipitation methods, respectively. The corresponding calcined samples were marked as PtInHT-XC (X represents morphology of F-flower-like, $\mathrm{P}$-single-plate and $\mathrm{M}-$ block mass). After PDH reaction, the catalysts used were labeled as PtInHT-XU. During the preparation process, the HT-X, HT-XC, InHT-X and InHT-XC samples were also prepared. The structure and physic-chemical properties of catalysts and precursors were studied. The promoted effects of HT reconstruction on the microstructure and morphology of the 3D oxide nanosheet array catalyst, and the subsequently superior PDH performance, were profoundly discussed.

\section{Results and Discussion}

\subsection{Phase Structure and Reconstruction Study}

In order to ascertain the crystal phase structure of all samples in details, the XRD patterns of precursors, calcined and reduced samples are shown together in Figure 1, and the analyzing results of XRD patterns of all samples before calcination are given in Table 1.

It can be seen that the XRD patterns of HT-F, HT-P and HT-M exhibit strong characteristic diffraction peaks in the HT phase [32], although their preparation processes are different. After calcination, followed by the impregnation of HT-FC, HT-PC and HT-MC with $\mathrm{In}^{3+}$ ions, the characteristic diffraction peaks of the HT phase appear again in the XRD patterns of InHT-F, InHT-P and InHT-M, without other diffraction peaks. That suggests that the impregnation condition is beneficial to reconstructing the HT phase. A similar HT recrystallization phenomenon happened again after the impregnation of In-based metal oxides with $\mathrm{Pt}^{4+}$ ions. For HT-M, the broad and well-defined diffraction peaks indicate that the obtained single HT phase was poorly crystallized. With the introduction of $\mathrm{In}^{3+}$ ions and further $\mathrm{Pt}^{4+}$ ions, the relative intensity of diffraction peaks of HT phase gives a decreasing tendency. From HT-F 
to InHT-F and HT-P to InHT-P, the shrinkage of peak intensities is more considerable than that from HT-M to InHT-M. This should be related to the decrease of HT crystallinity. At the same time, the average crystallite size in the $c$ direction $(L c)$ also decreases with reconstruction and even drops from PtInHT-M to PtInHT-P and to PtInHT-F (see Table 1), which can be estimated by means of the Scherrer equation [33]. This indicates that the HT layer becomes thinner and thinner.

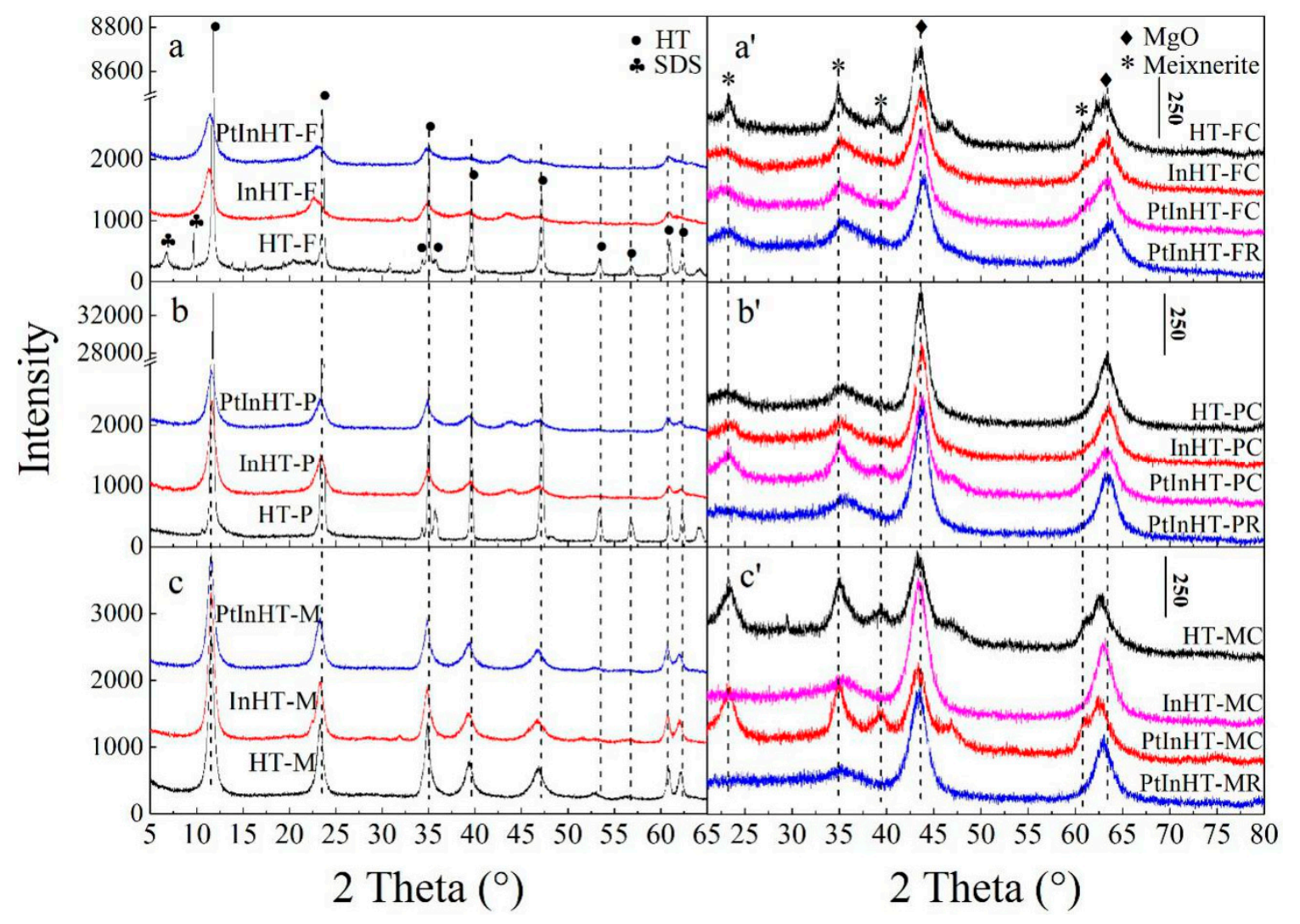

Figure 1. XRD patterns of HT precursors and derived samples in different morphology.

Table 1. Lattice parameters of HT phase in all dried samples.

\begin{tabular}{|c|c|c|c|c|}
\hline \multicolumn{2}{|c|}{ Sample } & \multirow{2}{*}{$\begin{array}{c}\text { Lattice Parameter } a(\mathrm{~nm})^{\mathbf{a}} \\
0.3037\end{array}$} & \multirow{2}{*}{$\begin{array}{c}\text { Lattice Parameter } c(\mathbf{n m}){ }^{\mathbf{b}} \\
2.2551\end{array}$} & \multirow{2}{*}{$\begin{array}{c}\operatorname{Lc}(\mathbf{n m})^{\mathrm{c}} \\
233.5\end{array}$} \\
\hline & $-F$ & & & \\
\hline \multirow[t]{3}{*}{$\mathrm{HT}$} & $-\mathrm{P}$ & 0.3039 & 2.2588 & 235.7 \\
\hline & $-\mathrm{M}$ & 0.3045 & 2.2847 & 64.1 \\
\hline & $-F$ & 0.3051 & 2.3246 & 34.2 \\
\hline \multirow[t]{3}{*}{ InHT } & $-P$ & 0.3041 & 2.2673 & 48.4 \\
\hline & $-\mathrm{M}$ & 0.3049 & 2.2858 & 60.1 \\
\hline & $-F$ & 0.3052 & 2.3027 & 42.6 \\
\hline \multirow[t]{2}{*}{ PtInHT } & $-P$ & 0.3049 & 2.2764 & 44.2 \\
\hline & $-\mathrm{M}$ & 0.3050 & 2.2936 & 51.3 \\
\hline
\end{tabular}

a $a=2 d_{110 .}{ }^{\mathrm{b}}$ Average value calculated from (003), (006), and (009) reflections. ${ }^{\mathrm{c}}$ Average crystallite size in c direction calculated from the Scherrer equation using the FWHM (Full Width at Half Maximum) of (003) and (006) reflections [33].

Additionally, the decreasing $\mathrm{M}^{2+} /\left(\mathrm{M}^{3+}+\mathrm{M}^{4+}\right)$ ratio can cause the increase of positive charge density in the layers, while the big radii of $\mathrm{In}^{3+}\left(0.080 \mathrm{~nm}\right.$, the Shannon ionic radis [34]) and $\mathrm{Pt}^{4+}$ (0.063 nm, Shannon ionic radius [34]) ions can broaden the distance of metal ions in the layers. These can make the octahedral cell shrink or expand and then influence the value of the lattice parameter $a$ and $c$ of HT phase, as shown in Table 1. The change of lattice parameters $a$ and $c$ of the HT phase (Table 1) demonstrates that $\mathrm{In}^{3+}$ and $\mathrm{Pt}^{4+}$ ions have been introduced into the HT layer. It signifies that 
the Pt and in species could be highly dispersed on the final metal oxides with close contact among them, and support [10].

After calcination and reduction, the HT phase disappears along with the occurrence of $\mathrm{MgO}$ (JCPDS file number 45-0946) and meixnerite $\left(\mathrm{Mg}_{4} \mathrm{Al}_{2}(\mathrm{OH})_{14} \cdot 3 \mathrm{H}_{2} \mathrm{O}\right.$, JCPDS file number 35-0964) diffraction peaks in Figure 1. At the same time, there are not any metal phase diffraction peaks can be found in the XRD patterns, which means that $\mathrm{Pt}$ and/or in metal phases are exactly evenly-dispersed on the surface of HT-derived catalysts.

From TEM images of PtInHT-FR, PtInHT-PR and PtInHT-MR in Figure 2, it is difficult to find metal particles except thin nanosheets. That indicates that the metal particles are so small that the TEM cannot identify them. Therefore, it is reasonable to infer that metal atom clusters or single metal atoms are possibly formed on the surface of metal oxide nanosheets due to the low metal loading amount and the HT lattice confinement effect [10]. The EDS element-mapping images of PtInHT-FR further demonstrate the uniform distribution of $\mathrm{Pt}$ and in elements without aggregation, and support the probability of metal atoms or atom clusters type distributions [35].
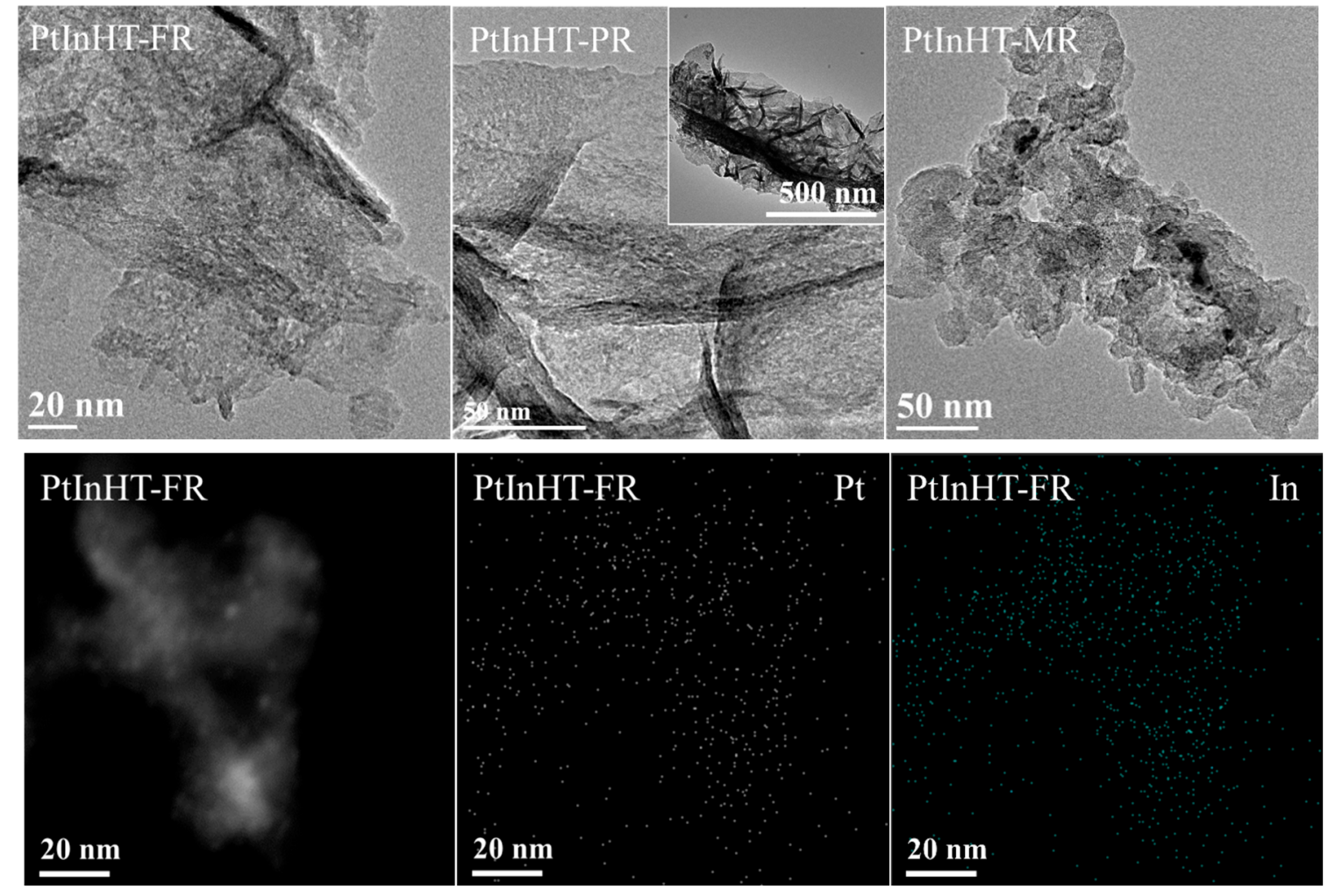

Figure 2. TEM images of reduced samples: PtInHT-FR, PtInHT-PR, PtInHT-MR and EDS element-mapping analysis of PtInHT-FR. In the abbreviations: F-flower-like, $\mathrm{P}$ - single-plate, and $\mathrm{M}$-block mass and $\mathrm{R}$-reduced sample.

\subsection{Morphology, Texture and Pt-In Interaction Analysis}

Figure 3 shows SEM images of three series of samples. It clearly depicts that the HT-F and corresponding derivative samples are constructed by huge ball-flower-like microstructure. For fresh HT-P and its derivative samples, perfect single-plate NPs are displayed in the SEM images. On the contrary, small, flakes are disorderly stacked into big block masses for HT-M and its derivative products. The calcination makes the nanosheets become rough and the impregnation-induced reconstruction makes them become smooth again. The loose surface for the calcined samples is related to the newly formed pores, which is the result of the decomposition and removal of interlayer anions and hydroxyl groups. It is clear that a large amount of small and ultrathin nanosheets grow in an orderly manner with $a b$-planes interdigitated perpendicular to the two lateral surfaces of recrystallizing original HT 
nanosheets for InHT-F and InHT-P. According to the XRD results in Figure 1, the reconstruction should also take place in InHT-M, although it is difficult to distinguish the small new nanosheets from the original flakes. In other words, this microstructure is indistinctive in the reconstructed HT-M series and instead severely aggregated nanoplates without any regular shape leave over. This microstructure should be the result of abundant hydroxyl groups on the edge sites and the basal plane of calcined HT plates [36]. The similar morphology can be seen in the SEM images of corresponding PtIn-based samples. In any case, there must be a strong interaction between the newly formed nanoplates and the initial huge templates, originating from the shared $\mathrm{Al}$ and other elements [36]. The strong interaction is beneficial to stabilize and disperse metal active species. The formation of ultrathin nanosheets is bound to decrease the average crystallite size in the $c$ direction (Table 1) and weaken the diffraction peaks of HT phase in initial huge HT-F and HT-P template, which is consistent with the XRD results in Figure 1. As for the reduced samples, the basic morphology feature still can be maintained, but some broken particles can be found on the surface of single-plate PtInHT-PR sample. That indicates that the fully opening surface is detrimental to protect the newly formed nanosheets from destruction by an external force.
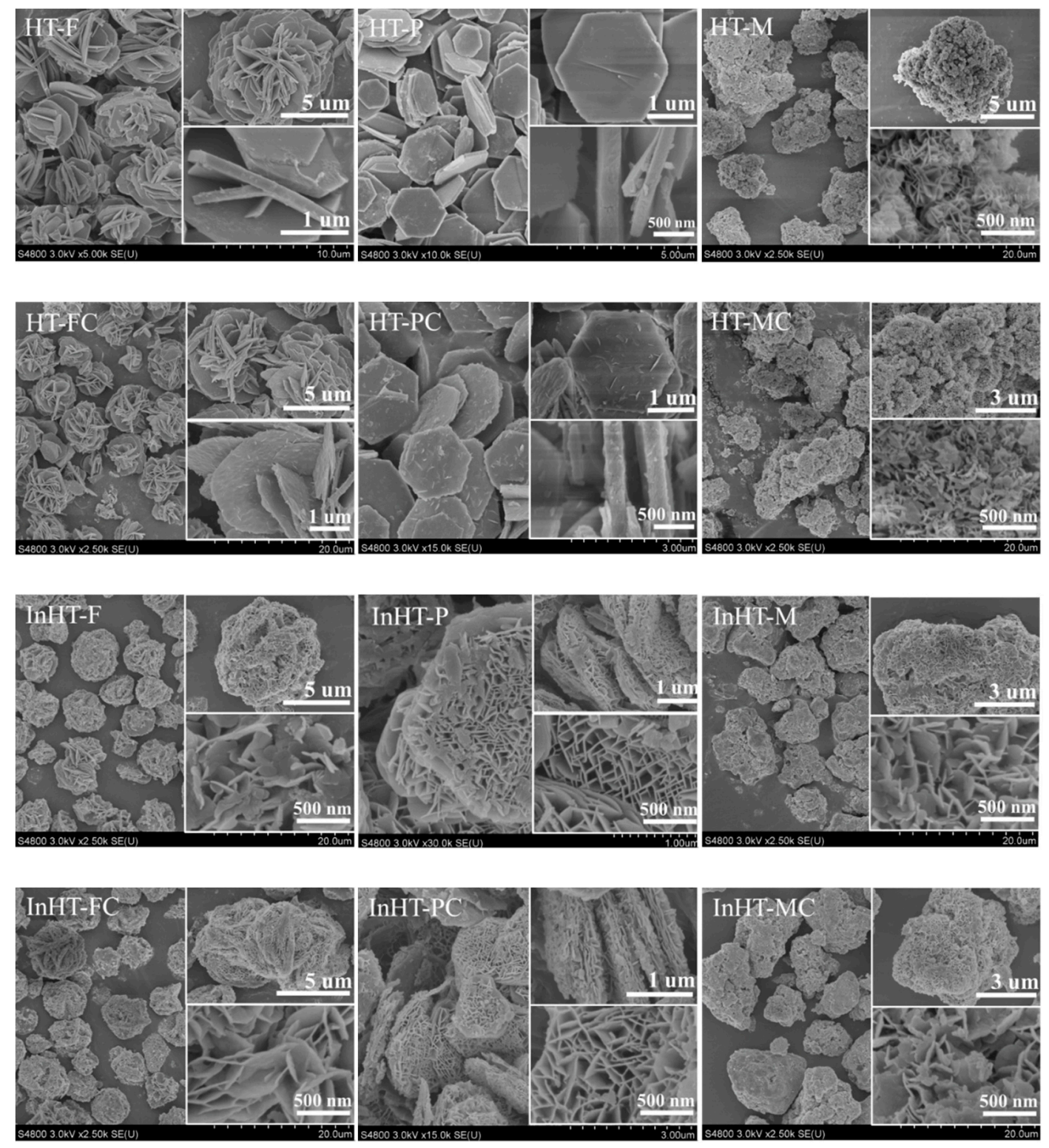

Figure 3. Cont. 

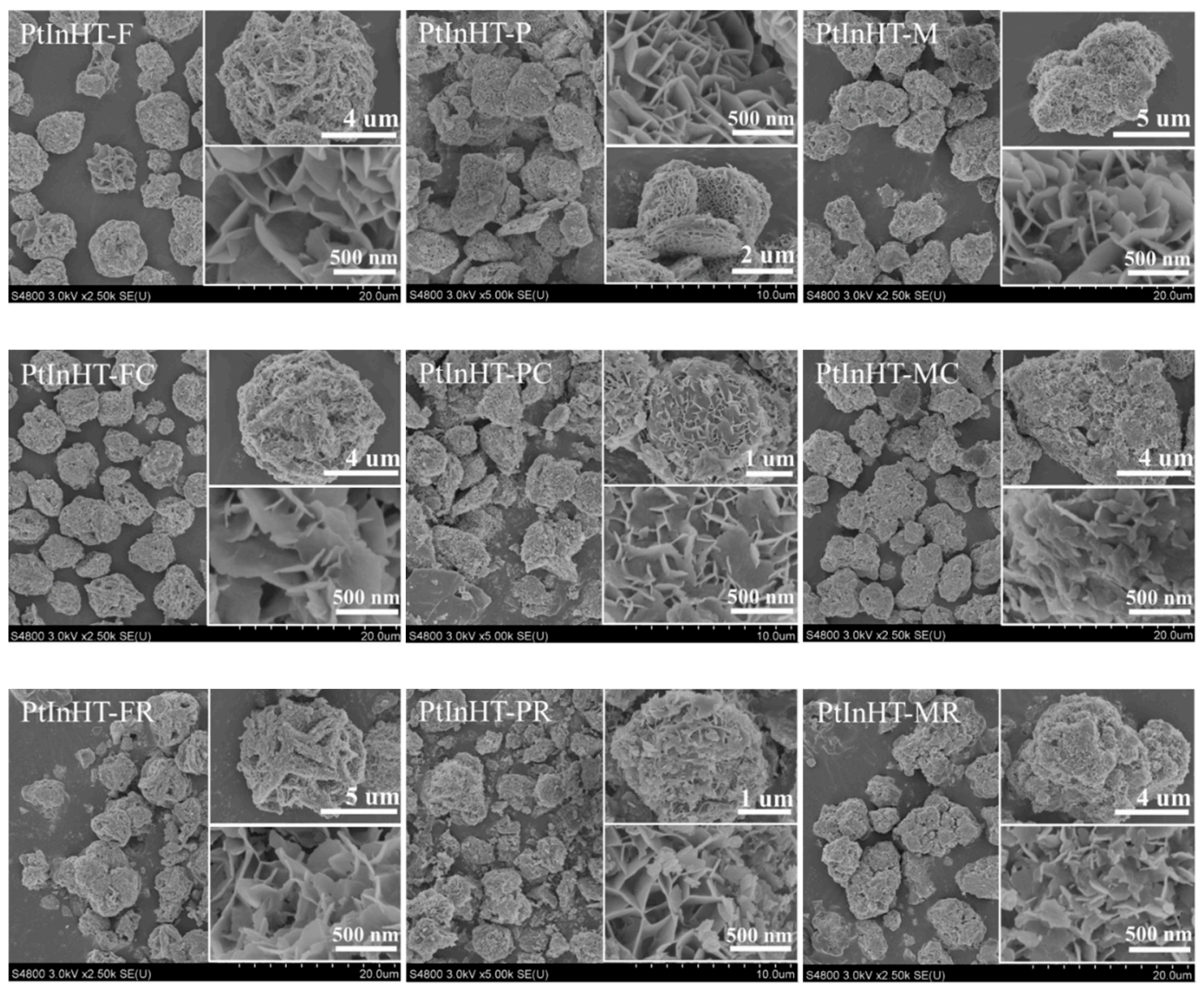

Figure 3. SEM images of HT precursor, calcined, reconstructed and reduced samples with different morphologies.

It can be seen that the slit-shaped mesopores are the common features of all samples. As for the recrystallizing single-plate samples, including InHT-P, PtInHT-P and corresponding calcined and reduced products, the reconstruction not only results in the formation of narrow slit-like pores due to the nanoplates' delaminating, but also leads to the appearance of honeycomb-like pores arising from the growth of ultrathin nanosheets perpendicular to the surface of the primary large single-plate nanoplates. Especially in the InHT-F and PtInHT-F series, the big wedge-shaped pore channels appear in the huge ball-flower-like microstructure, except the honeycomb-like pores. However, the similar size between the original flakes and newly formed nanosheets make the pore structures of the HT-M and reconstructed samples no different. Therefore, the obvious hierarchical pore feature can be assigned to recrystallizing flower-like and single-plate samples; and the pore shape and size of recrystallizing flower-like samples are more complicated than those of single-plate samples.

Low-temperature $\mathrm{N}_{2}$ adsorption-desorption isotherms and pore-size distribution (PSD) curves were conducted to evaluate the textural properties of PtInHT-FC, PtInHT-PC and PtInHT-MC. Their plots are shown in Figure 4 and the corresponding $S_{\mathrm{BET}}, V_{\mathrm{p}}$ and $d_{\mathrm{p}}$ are given in Table 2. According to the isotherm classification, all samples exhibit a type IV isotherm with $\mathrm{H} 3$ hysteresis loops, implying the presence of typical slit-shaped mesopores $[8,24]$. The PSD curves and $d_{\mathrm{p}}$ values show that the pore size increases in the following order, PtInHT-FC $<$ PtInHT-PC $<$ PtInHT-MC, and the same trend can be found for their $S_{\text {BET }}$ values. 

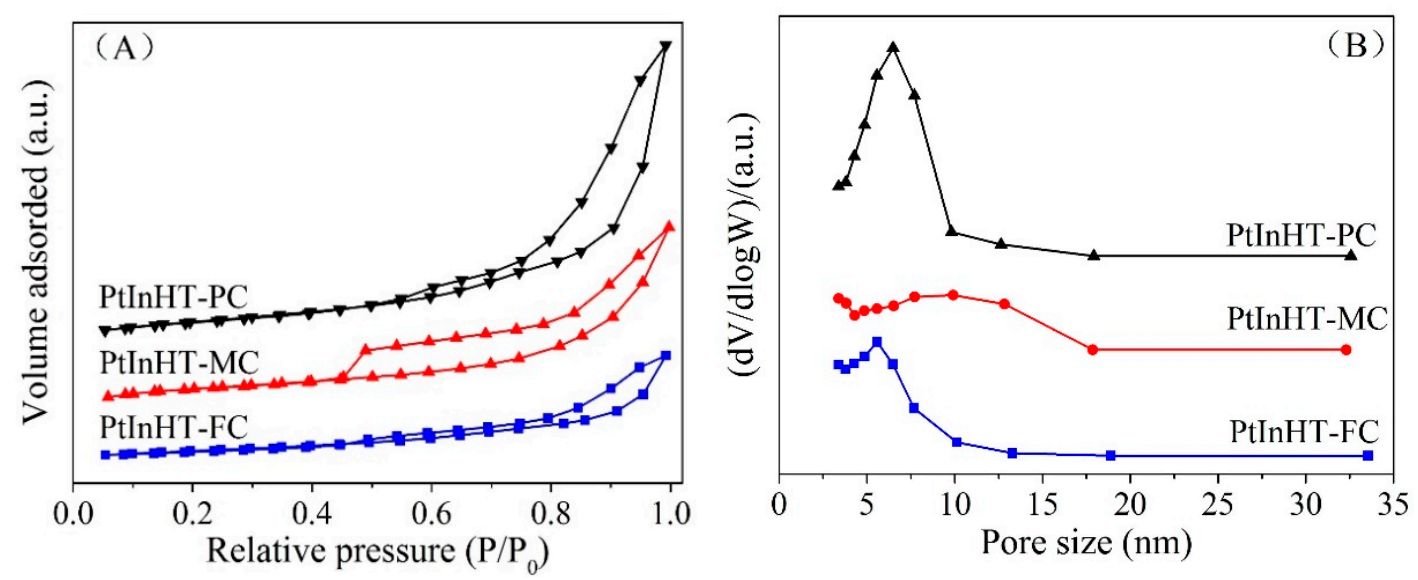

Figure 4. (A) Low temperature $\mathrm{N}_{2}$ adsorption-desorption isotherms and (B) PSD curves of different catalysts.

Table 2. Textural properties and the dispersion degree of $\mathrm{Pt}(\mathrm{DPt})$ for PtInHT-XC catalysts.

\begin{tabular}{ccccc}
\hline Sample & $S_{\text {BET }}{ }^{\mathbf{a}}\left(\mathbf{m}^{\mathbf{2}} \cdot \mathbf{g}^{-\mathbf{1}}\right)$ & $V_{\mathbf{p}} \mathbf{b}^{\mathbf{b}}\left(\mathbf{c m}^{\mathbf{3}} \cdot \mathbf{g}^{-\mathbf{1}}\right)$ & $d_{\mathbf{p}}{ }^{\mathbf{c}}(\mathbf{n m})$ & $D_{\mathbf{P t}}{ }^{\mathbf{d}} \mathbf{( \% )}$ \\
\hline PtInHT-FC & 57.9 & 0.17 & 5.58 & 33.6 \\
PtInHT-PC & 131.6 & 0.48 & 6.48 & 21.1 \\
PtInHT-MC & 144.4 & 0.31 & 9.91 & 27.3 \\
\hline
\end{tabular}

a BET specific surface area. ${ }^{b}$ Total pore volume. ${ }^{c}$ The most probable pore size determined by the BJH method. ${ }^{\mathrm{d}} \mathrm{Pt}$ dispersion of PtInHT-XR determined by the pulse chemisorption of CO.

The broad PSD was in the mesopore range; big $d_{\mathrm{p}}$ and $S_{\mathrm{BET}}$ values of PtInHT-MC are related to unordered aggregation of small, flakey-like particles. As expected, the big, ordered nanosheets make PtInHT-FC and PtInHT-PC present the narrow PSD feature, and small $d_{\mathrm{p}}$ and $S_{\text {BET }}$ values. The $V_{\mathrm{p}}$, $d_{\mathrm{p}}$ and $S_{\mathrm{BET}}$ values of PtInHT-FC are far lower than that of PtInHT-PC especially, which is attributed to the fully open surface of PtInHT-PC relative to that of PtInHT-FC.

XPS analysis was applied to investigate the surface chemical state and relative concentration of In element on the reduced samples. The broad $\operatorname{In} 3 \mathrm{~d}_{5 / 2}$ and $\operatorname{In} 3 \mathrm{~d}_{3 / 2}$ peaks of catalysts can be deconvoluted into two peaks, respectively, in Figure 5. The deconvolution results of the corresponding spectra are listed in Table 3. The low bind energy (BE) contribution is assigned to metallic state $\operatorname{In}\left(\operatorname{In}^{0}\right)$, and the high one is related to oxidation state $\operatorname{In}\left(\mathrm{In}^{3+}\right)$. A slightly decreasing BE value of $\operatorname{In}^{0}$ from PtInHT-FR to PtInHT-PR and to PtInHT-MR reflects the weakening electrons' transfer from metallic In to Pt species and the Pt-In interaction. Additionally, a slightly increased ratio of $\mathrm{In}^{3+} / \mathrm{In}^{0}$ can be seen in Table 3, in accordance with the order of PtInHT-MR, PtInHT-PR and PtInHT-FR. This indicates that the flower-like hierarchical structure with porous channels is in favor of maintaining the In element in $\mathrm{In}^{3+}$ ions rather than $\operatorname{In}^{0}$ states, while the $\mathrm{In}^{3+}$ ions in PtInHT-MR, with small, flakey NPs, can easily be reduced.

It is worth mentioning that PtInHT-FC exhibits a higher surface Pt density than that of PtInHT-PC and PtInHT-MC, due to its low $S_{\mathrm{BET}}$ and high $D_{\mathrm{Pt}}$, as listed in Table 2. In addition, the relative content of surface, metallic-state In increases in the order of PtInHT-FR, PtInHT-PR and PtInHT-MR (see Figure 5 and Table 3). Therefore, it can be inferred that the most of the surface In species have a chance to make close contact with Pt species and form plenty of strongly interacting Pt-In centers over PtInHT-FR. Accordingly, the Pt-In interaction over PtInHT-PR and PtInHT-MR should be decreased and weakened due to their low $D_{\mathrm{Pt}}$ and high $S_{\mathrm{BET}}$. Additionally, too much In over PtInHT-MR could block Pt sites, thus cause a disadvantageous influence to the $\mathrm{PDH}$ reaction $[8,24]$.

On the basis of the aforementioned results and preparation conditions, the formation of a ball-flower-like and single-plate hierarchical microstructure is tentatively proposed in Scheme 1. 


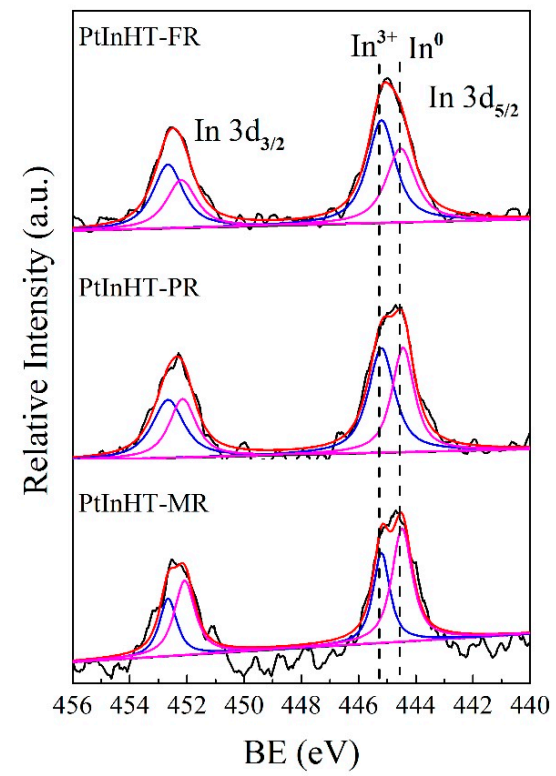

Figure 5. XPS spectra of the In 3D region of reduced catalysts.

Table 3. XPS results of reduced catalysts.

\begin{tabular}{|c|c|c|c|c|c|}
\hline \multirow{3}{*}{ Catalyst } & \multicolumn{4}{|c|}{ BE $(e V)$} & \multirow{3}{*}{$\operatorname{In}^{3+} / \operatorname{In}^{0 \mathrm{a}}$} \\
\hline & \multicolumn{2}{|c|}{$\operatorname{In} 3 d_{5 / 2}$} & \multicolumn{2}{|c|}{$\operatorname{In}_{3} d_{3 / 2}$} & \\
\hline & $\operatorname{In}^{3+}$ & $\operatorname{In}^{0}$ & $\mathrm{In}^{3+}$ & $\operatorname{In}^{0}$ & \\
\hline PtInHT-FR & 445.2 & 444.5 & 452.7 & 452.2 & 1.34 \\
\hline PtInHT-PR & 445.2 & 444.4 & 452.7 & 452.1 & 1.17 \\
\hline PtInHT-MR & 445.2 & 444.4 & 452.7 & 452.0 & 0.66 \\
\hline
\end{tabular}

${ }^{\text {a }}$ Peak area ratio of the oxidation state In to metallic state In.

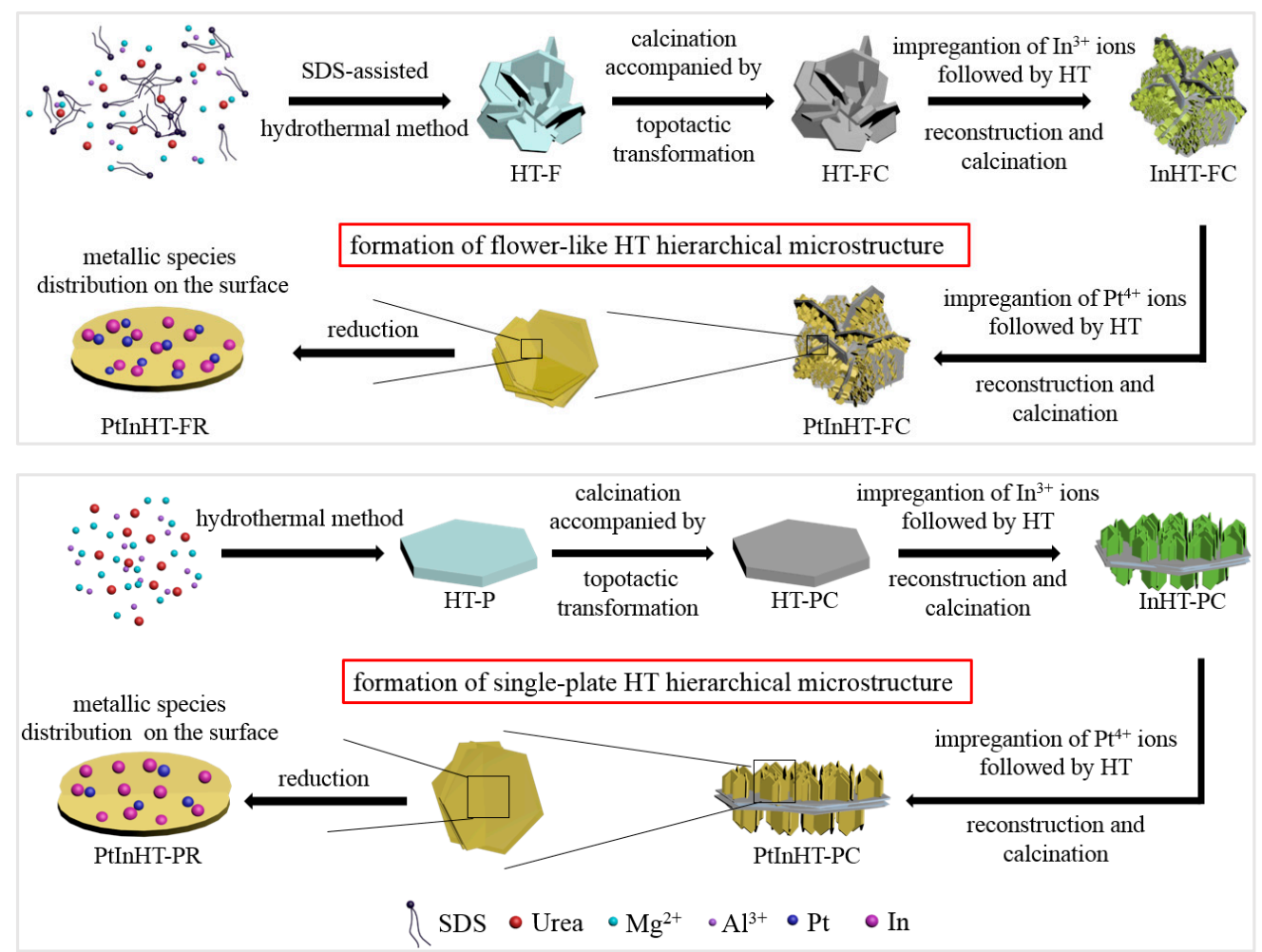

Scheme 1. Schematic illustrations of the formation of the ball-flower-like and single-plate hierarchical microstructure. 


\subsection{Catalytic Performance and Structure-Activity Relationship Discussion}

To investigate the performance, three catalysts were evaluated in the PDH reaction. Figure 6 presents the propane conversion and propene selectivity against time for these catalysts. The homogeneous reaction is also tested in the blank tube and the propane conversion and propene selectivity as functions of time are shown in Figure S1. It was found that the conversion of propane is only around 1\%, with a propene selectivity of around $65 \%$. This indicates that the contribution of homogeneous reaction can be ignored. As shown in Figure S2, the selectivities to by-products (methane, ethane and ethene) are very low and can be ignored. In the PDH reaction, the initial propane conversions for PtInHT-FR, PtInHT-PR and PtInHT-MR are 6\%, 44\% and 28\%, respectively. After a long induction period of $20 \mathrm{~h}$, the propane conversion and propene selectivity of PtInHT-FR can be stabilized at above $40 \%$ and $97 \%$ with a maximum conversion of $48 \%$. Until upon $190 \mathrm{~h}$ of time on stream, the conversion of PtInHT-FR only decreases to $36 \%$. Despite a high initial conversion with a short induction period of around $5 \mathrm{~h}$, a smooth stable period for around $50 \mathrm{~h}$ can be achieved by PtInHT-PR. A decreased propene selectivity cannot be ignored during the whole reaction process. As for PtInHT-MR, the reaction only can run for $20 \mathrm{~h}$ with moderate initial conversion; in the same period, the propene selectivity decreases severely with the rising propane conversion.

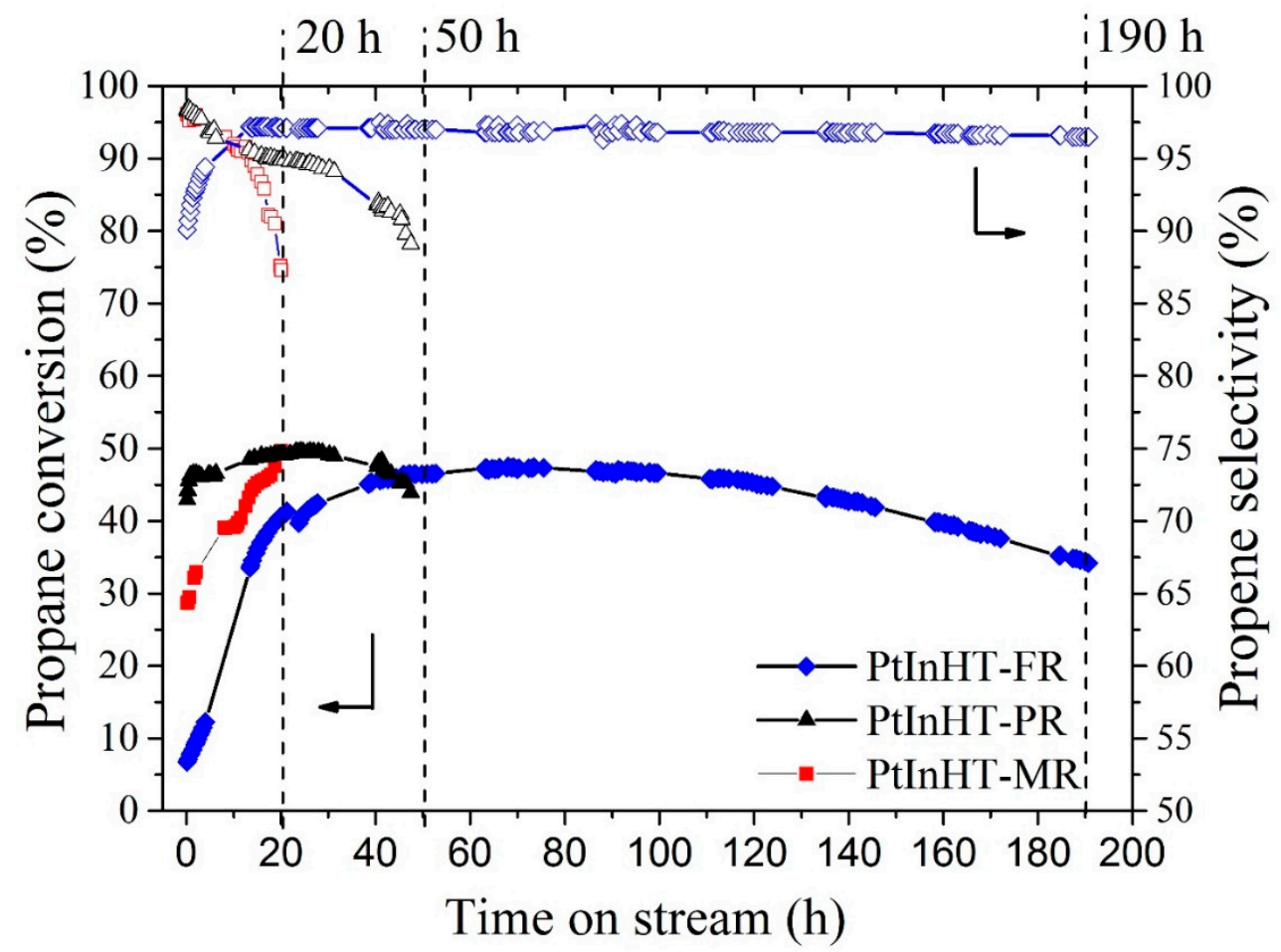

Figure 6. Propane conversion and propene selectivity as functions of time for different catalysts (reaction conditions: $\mathrm{T}=600{ }^{\circ} \mathrm{C}, \mathrm{H}_{2}: \mathrm{C}_{3} \mathrm{H}_{8}: \mathrm{N}_{2}=7: 8: 35$ (molar ratio), weight hourly space velocity $\left.(\mathrm{WHSV})=3 \mathrm{~h}^{-1}, \mathrm{~m}_{\text {cat }}=0.4 \mathrm{~g}\right)$.

After the reaction, the XRD patterns of used samples are shown in Figure 7. It can be found that the meixnerite phase is still retained in the used PtInHT-FU, which is supposed to be favorable for the $\mathrm{PDH}$ reaction [7]. Additionally, the change occurs from fresh PtInHT-FR having more MgO phase (see Figures 1 and 7) while the used one has more meixnerite phase. This phase transfer of support could be the one cause of induction of performance during reaction. In addition, a new diffraction peak appears at around $26.0^{\circ}$ in all the used samples, which belongs to the carbon deposits (JCPD file number 44-1644). The diffraction peak intensity of carbon deposits increases following the order: PtInHT-PU > PtInHT-MU > PtInHT-FU, which must be consistent with the amount of deposited carbon. 


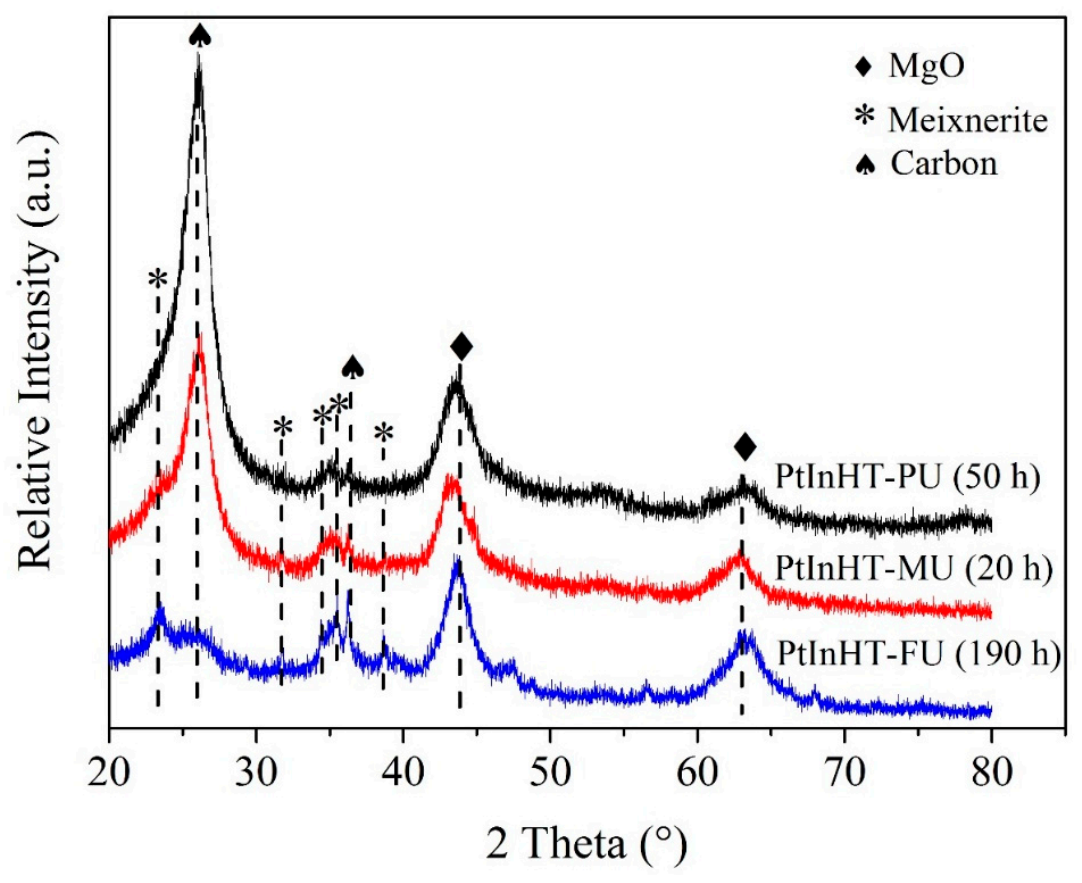

Figure 7. XRD patterns of used catalysts with different reaction time.

As shown in Figure 8, a large amount of carbon deposits with different sizes and morphologies, including granule, stick, loop and so on, are formed on the surface of used catalysts after reactions. Moreover, even the morphology features of PtInHT-PU and PtInHT-MU disappear, due to the surface coverage and pore blockage by carbon deposits. However, the flower-like particles of PtInHT-FU are still well dispersed and recognizable after a long reaction time, reflecting the fact that the amount of carbon deposits on PtInHT-FU number fewer than those on PtInHT-PU and PtInHT-MU. The most important thing is that the carbon is only deposited on the partial pore channel mouth of PtInHT-FU, meaning the active sites in the pore channels have no chance to be covered by the deposited carbon.

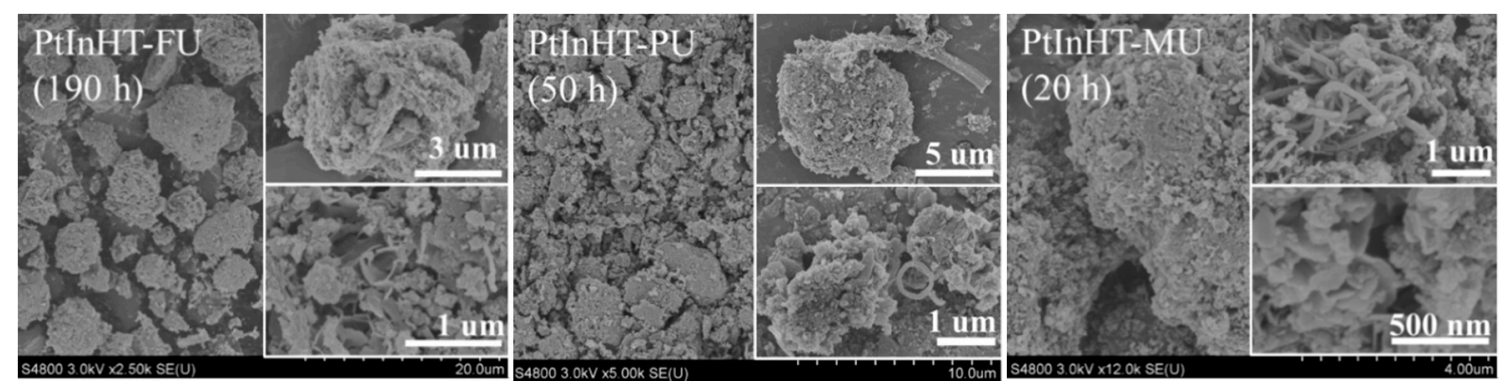

Figure 8. SEM images of used catalysts with different reaction time.

In order to determine the degree of carbon deposition during PDH reaction, TG experiments were conducted over the used catalysts. As shown in Figure 9, the mass loss of all samples must be related to the removal of deposited carbon. The amount of deposited carbon on the catalysts used increases following the order of PtInHT-FU, to PtInHT-MU and finally to PtInHT-PU. The low carbon amount is the most important factor to extend the lifetime of the flower-like PtInHT-FU.

After $190 \mathrm{~h}$ of reaction, it is still difficult to pick out metallic particles from the TEM images of PtInHT-FU in Figure 10. However, the Pt particles can be found on the surface of PtInHT-PU and PtInHT-MU. According to the particle size distribution of PtInHT-MU, the average particle size is higher for PtInHT-MU $(5.5 \mathrm{~nm})$ than that for PtInHT-PU $(3.2 \mathrm{~nm})$. That implies that the metallic particles on PtInHT-FU are more stable than those on PtInHT-PU and PtInHT-MU under a high 
temperature reaction, which has a vital influence for the performance of PDH. Certainly, the carbon deposits also can be easily found on the surface of all samples.

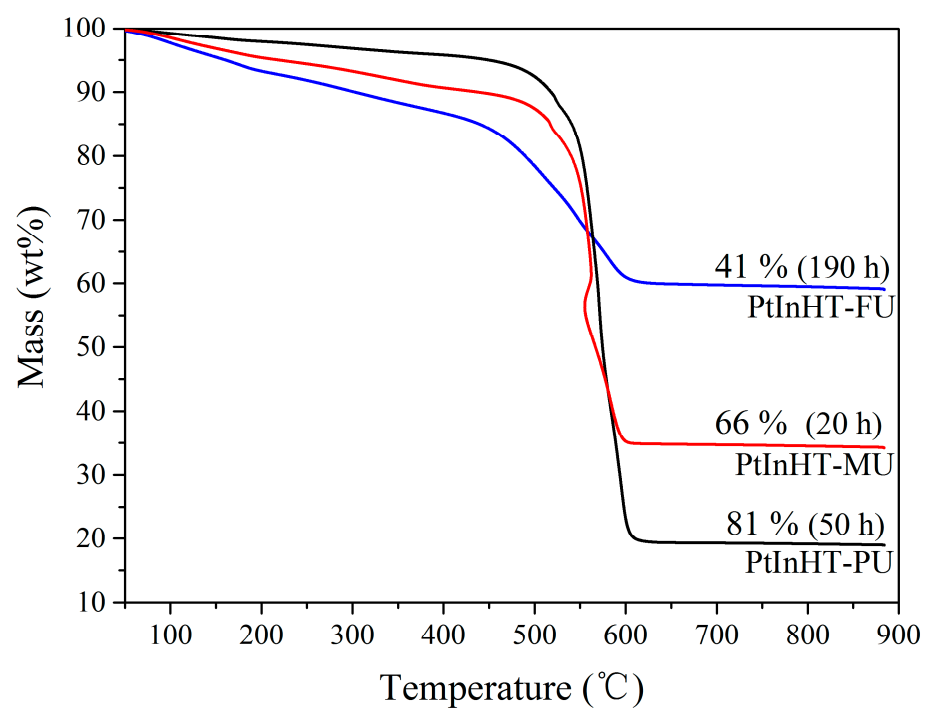

Figure 9. TG profiles of used catalysts with different reaction times.

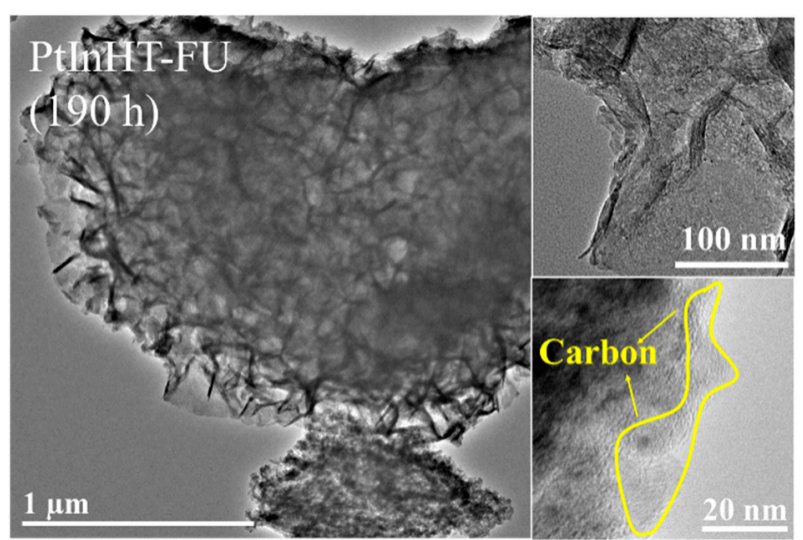

(A)

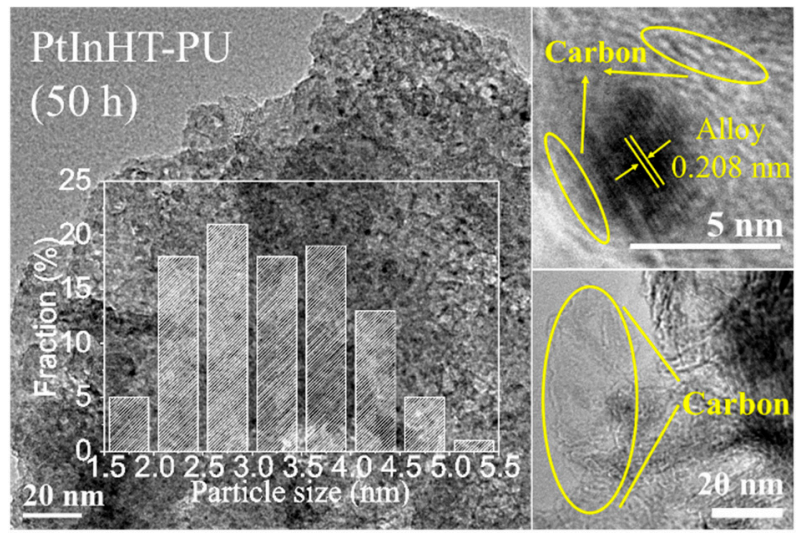

(B)

Figure 10. Cont. 


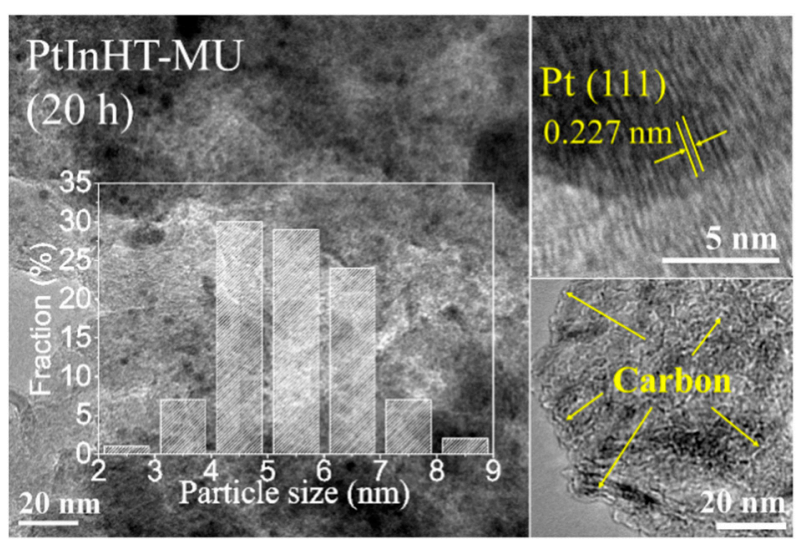

(C)

Figure 10. TEM images, HR-TEM and the statistics of particle size distributions in the insets of the used catalysts with different reaction times. (A) $190 \mathrm{~h},($ B) $50 \mathrm{~h}$ and (C) $20 \mathrm{~h}$.

The activity induction should be closely related with the partial coverage of the active metal surface by $\mathrm{In}_{2} \mathrm{O}_{3}$ species [7]. We propose that the covered, active Pt particles tend to slowly migrate from the support onto $\mathrm{In}_{2} \mathrm{O}_{3}$ particles to build highly dispersed "sandwich structure" of the $\mathrm{Pt}-\mathrm{In}_{2} \mathrm{O}_{3}$-support under the reaction atmosphere $[25,26]$. Therefore the duration of induction should be determined by the coverage degree of $\mathrm{In}_{2} \mathrm{O}_{3}$ species.

Although the maximum conversion is up to 50\%, the PDH reaction cannot be carried out after $50 \mathrm{~h}$ for PtInHT-PR and $20 \mathrm{~h}$ for PtInHT-MR due to the reactor blockage by a large amount of deposited carbon (see Figures 7-10), and the deposited carbon particles fully block the honeycomb-like pores of PtInHT-PR and cover the block mass particles of PtInHT-MR. Fortunately, the deposited carbon over PtInHT-FR after reacting for $190 \mathrm{~h}$ is much less than that over others. It is interesting to note that the carbon is mainly deposited on the pore mouth of ball-flower-like PtInHT-FR, which protects the metallic sites on the interior honeycomb-like surface of wedge-shaped pores.

Obviously, the deposited carbon amount is inversely correlated to the corresponding propene selectivity. The ball-flower-like multi-level hierarchical microstructure with abundant wedge-shaped pores, and short-channel honeycomb-like pores, but not the slit-like pores, is in favor of propane and propene diffusion. Furthermore, the low $S_{\text {BET }}$ of PtInHT-FR facilitates the propene desorption and then decreases the likelihood of deep dehydrogenation and hydrogenolysis on metal sites. These can be used to explain the high selectivity and low carbon deposits of PtInHT-FR. On the contrary, plenty of carbon deposits and the sharply reduced selectivities of PtInHT-PR and PtInHT-MR arise from the propene concentrating on the surface with a high $S_{\mathrm{BET}}$ value, which triggers carbon formation and accumulation.

Except for the influences of texture and morphology, the propene selectivity and catalytic stability can be improved, by partially transferring electrons from IN to Pt [11]. PtInHT-FR presents a high surface $\mathrm{In}^{3+} / \mathrm{In}^{0}$ ratio and $\mathrm{BE}$ value of $\mathrm{In}^{0}$, indicating that a high electron density of Pt and strong Pt-In interaction can be obtained (see Figure 5 and Table 3), which facilitates the desorption of propene and the migration of carbon precursors from the metal surface to the support [7,11]. Moreover, the suitable $\mathrm{In}^{0}$ species can strengthen the Pt-In-support interaction, improve dispersion and prevent sintering of Pt particles (see Figures 2 and 10), stabilizing the catalytic performance of PtInHT-FR. Meanwhile, the overabundant $\operatorname{In}^{0}$ species could bring about a disadvantageous influence to the PDH reaction. The high content $\operatorname{In}^{0}$ species in PtInHT-PR and PtInHT-MR can not only block Pt active sites [8], but also weaken Pt-In interactions and lead to the Pt sintering (see Figures 2, 8 and 10). This is associated with the fact that the carbon deposits can easily form on the large-size Pt sites over PtInHT-PR and PtInHT-MR [37]. 
The regeneration and activation test for PtInHT-FU is shown in Figure 11. After each regeneration, the activity can be restored up to the level before regeneration, but decreases rapidly; almost no change in the selectivity can be observed. Although, the deposited carbon can be removed by a simple oxidation process (not the industrial condition), but the regeneration conditions can cause $\mathrm{Pt}$ sintering and decrease the $\mathrm{Pt}$ dispersion to a certain extent, which can result in the decrease of initial activity with cycles of regeneration [38,39].
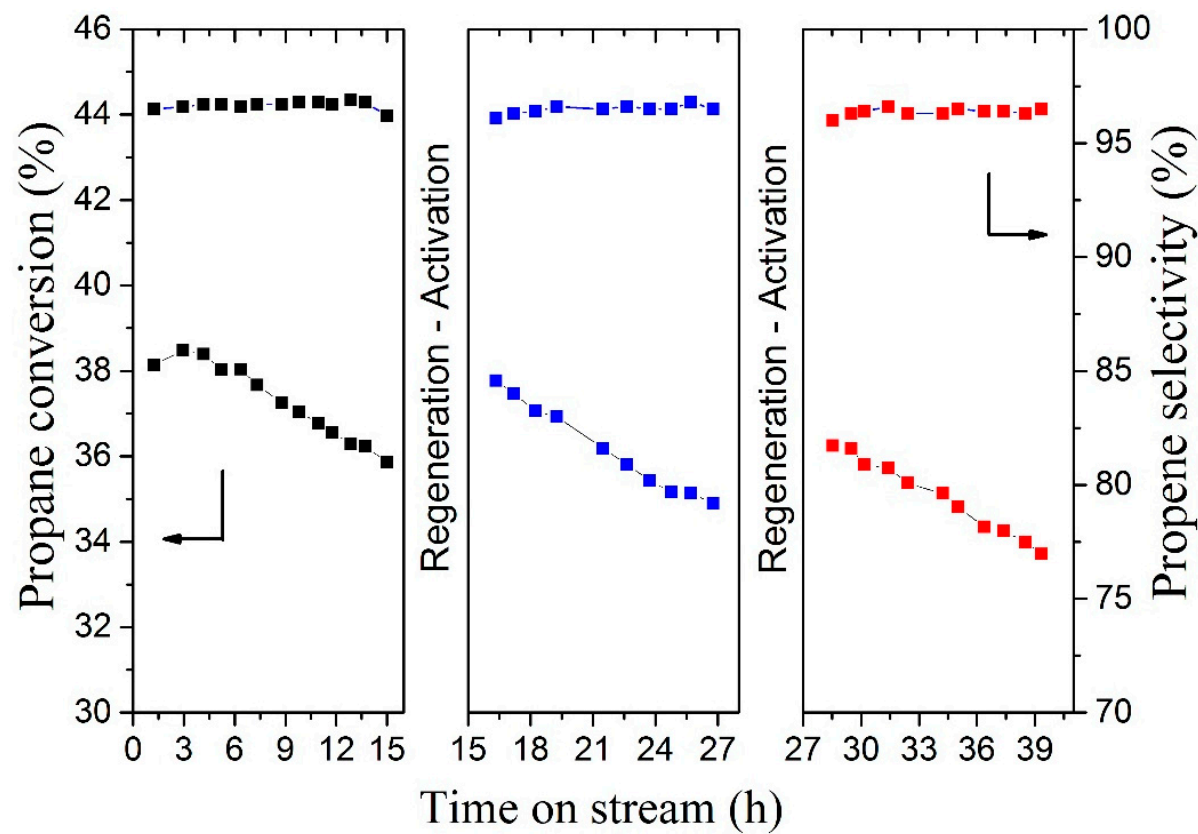

Figure 11. Propane conversion and propene selectivity as function of time for PtInHT-FU after regeneration and activation (regeneration conditions: $\mathrm{T}=600^{\circ} \mathrm{C}$, oxidation in air for $2 \mathrm{~h}$, sequencing purge with $\mathrm{N}_{2}$ for $30 \mathrm{~min}$ and then reduction in $5 \mathrm{vol} \% \mathrm{H}_{2} / \mathrm{N}_{2}$ for $2 \mathrm{~h}$; reaction conditions: $\mathrm{T}=600{ }^{\circ} \mathrm{C}$, $\mathrm{H}_{2}: \mathrm{C}_{3} \mathrm{H}_{8}: \mathrm{N}_{2}=7: 8: 35$ (molar ratio) and WHSV $=3 \mathrm{~h}^{-1}$ and $\mathrm{m}_{\text {cat }}=0.4 \mathrm{~g}$ ).

\section{Materials and Methods}

\subsection{Materials}

$\mathrm{Mg}\left(\mathrm{NO}_{3}\right)_{2} \cdot 6 \mathrm{H}_{2} \mathrm{O}, \mathrm{Al}\left(\mathrm{NO}_{3}\right)_{3} \cdot 9 \mathrm{H}_{2} \mathrm{O}$, urea and sodium dodecyl sulfate (SDS) were all of analytical purity. $\mathrm{H}_{2} \mathrm{PtCl}_{6} \cdot 6 \mathrm{H}_{2} \mathrm{O}$ powder was at $99.6 \%$ purity. All the chemicals were purchased from Fuchen (Tianjin) chemical reagent co. LTD (Tianjin, China).

\subsection{Preparation}

The flower-like precursor (HT-F) was prepared by a hydrothermal method. $0.82 \mathrm{~g} \mathrm{Mg}\left(\mathrm{NO}_{3}\right)_{2} \cdot 6 \mathrm{H}_{2} \mathrm{O}$, $0.6 \mathrm{~g} \mathrm{Al}\left(\mathrm{NO}_{3}\right)_{3} \cdot 9 \mathrm{H}_{2} \mathrm{O}, 0.2 \mathrm{~g}$ SDS and $6 \mathrm{~g}$ urea were dissolved in $65 \mathrm{~mL}$ deionized water, then moved into a $100 \mathrm{~mL}$ Teflon autoclave. After aging at $100^{\circ} \mathrm{C}$ for $20 \mathrm{~h}$, the sample was filtered, washed with deionized water to neutrality and dried in air at $100^{\circ} \mathrm{C}$ overnight.

Single-plate precursor (HT-P) was prepared using the same method as HT-F, except with no addition of SDS.

Block mass precursor (HT-M) was prepared by coprecipitation method. First, $17.09 \mathrm{~g} \mathrm{Mg}\left(\mathrm{NO}_{3}\right)_{2} \cdot 6 \mathrm{H}_{2} \mathrm{O}$ and $12.50 \mathrm{~g} \mathrm{Al}\left(\mathrm{NO}_{3}\right)_{3} \cdot 9 \mathrm{H}_{2} \mathrm{O}$ were dissolved in $100 \mathrm{~mL}$ deionized water. Another solution was prepared with $8 \mathrm{~g} \mathrm{NaOH}$ and $10.6 \mathrm{~g} \mathrm{Na}_{2} \mathrm{CO}_{3}$ dissolved in $100 \mathrm{~mL}$ deionized water. Then, two solutions were mixed drop-wise, with strong stirring at room temperature for $2 \mathrm{~h}$. The $\mathrm{pH}$ value was controlled at about 10 . Subsequently, the mixed solution was aged at $65^{\circ} \mathrm{C}$ for $12 \mathrm{~h}$. The resulting suspension was filtered, washed with deionized water to neutrality and dried in air at $100^{\circ} \mathrm{C}$ overnight. 
All the precursors were calcined for $4 \mathrm{~h}$ at $600{ }^{\circ} \mathrm{C}$ to obtain the corresponding calcined samples, named HT-XC (X represents morphology, either F, P or M).

The corresponding In-based precursors, InHT- $X$, were acquired by incipient wetness impregnation method for calcined samples HT-XC with $\operatorname{In}\left(\mathrm{NO}_{3}\right)_{3} \cdot x \mathrm{H}_{2} \mathrm{O}$ aqueous solution at room temperature for $6 \mathrm{~h}$. Next, PtInHT-XC catalysts were prepared by successive incipient impregnation method. Firstly, HT-XC was impregnated with an $\operatorname{In}\left(\mathrm{NO}_{3}\right)_{3} \cdot x \mathrm{H}_{2} \mathrm{O}$ aqueous solution at room temperature for $6 \mathrm{~h}$ and later dried at $120^{\circ} \mathrm{C}$ for $12 \mathrm{~h}$ to obtain In-based precursors InHT-X, and then these solids were calcined at $550{ }^{\circ} \mathrm{C}$ for $4 \mathrm{~h}$; corresponding products were labeled InHT-XC. Finally, the same procedures and conditions were performed on InHT-XC impregnated with $\mathrm{H}_{2} \mathrm{PtCl}_{6} \cdot 6 \mathrm{H}_{2} \mathrm{O}$, except that the time of impregnation was $2 \mathrm{~h}$. After drying and calcination, the resulting solids were defined as PtInHT- $X$ and PtInHT-XC, respectively. The loadings of Pt and In were $0.48 \mathrm{wt} \%$ and $1.38 \mathrm{wt} \%$, respectively. After the reduction treatment under $5 \mathrm{vol} \% \mathrm{H}_{2} / \mathrm{N}_{2}$ at $600{ }^{\circ} \mathrm{C}$ for $2.5 \mathrm{~h}$, these samples were labeled PtInHT-XR. And the used catalysts were marked as PtInHT-XU.

\subsection{Characterizations}

X-ray diffraction (XRD) characterization was carried on a Bruker D8-Focus X-ray diffractometer (BRUKER AXS GMBH, Karlsruhe, Germany) by Ni-filtered $\mathrm{Cu} K \alpha$ radiation $(\lambda=0.15406 \mathrm{~nm}$ ) with a scan speed of $2 \theta=8^{\circ} \cdot \mathrm{min}^{-1}$.

Low-temperature $\mathrm{N}_{2}$ adsorption-desorption was performed at $77 \mathrm{~K}$ on a TriStar 3000 micromeritics apparatus (Micromeritics, Norcross, GA, USA) to collect the textural properties. Prior to measurements, the samples were outgassed under vacuum at $300{ }^{\circ} \mathrm{C}$ for $4 \mathrm{~h}$, and then the specific surface area of samples was calculated by the Brunauer-Emmett-Teller (BET) method; the pore size distribution (PSD) was determined by the Barrett-Joyner-Halenda (BJH) method, used upon the adsorption branch of the isotherms.

Field emission scanning electron microscopy (FESEM) was carried out on a Hitachi S- 4800 instrument (Tokyo, Japan) using a $3.0 \mathrm{kV}$ electron beam.

Transmission electron microscopy and energy dispersive spectroscopy (TEM-EDS) were performed on a JEM-2100F field-emission transmission electron microscope (JEOL, Tokyo, Japan) with an accelerating voltage of $200 \mathrm{kV}$.

The X-ray photoelectron spectra (XPS) of catalysts were recorded on a Thermo Scientific Escalab 250Xi X-ray photoelectron spectrometer (Thermo Fisher Scientific, Waltham, MA, USA) using Al K $\alpha$ $(h v=1253.6 \mathrm{eV})$ radiation. The BE was calibrated using the C1s level at 284.8 as an internal standard.

The dispersion degree of $\mathrm{Pt}\left(D_{\mathrm{Pt}}\right)$ was calculated by $\mathrm{CO}$ chemisorption. $\mathrm{CO}$ chemisorption was conducted on AutoChem II 2920 analyzer (Micromeritics, Norcross, USA). A total of $100 \mathrm{mg}$ of the samples were reduced under $10 \mathrm{vol} \% \mathrm{H}_{2} / \mathrm{Ar}$ atmosphere at $600{ }^{\circ} \mathrm{C}$ for $2 \mathrm{~h}$ with a heating rate of $10{ }^{\circ} \mathrm{C} \cdot \mathrm{min}^{-1}$. After reduction, the catalysts were swept with $\mathrm{He}$, at $600{ }^{\circ} \mathrm{C}$ for $30 \mathrm{~min}$, to remove $\mathrm{H}_{2}$, and then cooled down to $50{ }^{\circ} \mathrm{C}$. Subsequently, the $\mathrm{CO}$ pulse chemisorption was carried out at $50{ }^{\circ} \mathrm{C}$ by injecting pulses of $5 \mathrm{vol} \% \mathrm{CO} / \mathrm{He}$ until $\mathrm{CO}$ was adsorbed to saturation.

Thermogravimetric analysis (TG) was carried on a DTG-50/50H thermal analyzer (PerkinElmer, Waltham, MA, USA) to determine the carbon amount over the used catalysts with a heating rate of $10^{\circ} \mathrm{C} \cdot \mathrm{min}^{-1}$ from room temperature to $800^{\circ} \mathrm{C}$ in air.

\subsection{Catalytic Tests}

Propane dehydrogenation (PDH) reaction was carried out in a fixed-bed reactor. The calcined sample $(0.4 \mathrm{~g})$ was placed into the stainless-steel tube and reduced to a flow of $5 \mathrm{vol} \% \mathrm{H}_{2} / \mathrm{N}_{2}$ at $600{ }^{\circ} \mathrm{C}$ for $2.5 \mathrm{~h}$ with a rising rate of $5{ }^{\circ} \mathrm{C} \cdot \mathrm{min}^{-1}$. Afterwards, the $\mathrm{PDH}$ reaction was performed in a mixture of $\mathrm{H}_{2}, \mathrm{~N}_{2}$ and $\mathrm{C}_{3} \mathrm{H}_{8}\left(\mathrm{H}_{2}: \mathrm{C}_{3} \mathrm{H}_{8}: \mathrm{N}_{2}=7: 8: 35\right.$ (molar ratio) and WHSV $=3 \mathrm{~h}^{-1}$ ) at $600{ }^{\circ} \mathrm{C}$. The regeneration test was performed at $600{ }^{\circ} \mathrm{C}$, including oxidation in air for $2 \mathrm{~h}$, sequencing purge with $\mathrm{N}_{2}$ for $30 \mathrm{~min}$ and then reduction in $5 \mathrm{vol} \% \mathrm{H}_{2} / \mathrm{N}_{2}$ for $2 \mathrm{~h}$. The propane and gas products were analyzed by an online 
gas chromatograph equipped with a FID detector and an $\mathrm{Al}_{2} \mathrm{O}_{3}$ column. The propane conversion and propene selectivity were calculated as follows:

$$
\begin{aligned}
& \text { Propane conversion }(\%)=\frac{\text { propane, in }- \text { propane, out }}{\text { propane, in }} \times 100 \% \\
& \text { Propene selectivity }(\%)=\frac{\text { propene, out }}{\text { propane, in }- \text { propane, out }} \times 100 \%
\end{aligned}
$$

\section{Conclusions}

In conclusion, the ball-flower-like, single-plate and block mass $\mathrm{PtIn} / \mathrm{Mg}(\mathrm{Al}) \mathrm{O}$ catalysts were obtained by topological transformation and the reconstruction of HT precursors. The diversified morphology of catalysts was dependent on the conditions of synthesis. The metal ions of $\mathrm{Pt}^{4+}$ and $\mathrm{In}^{3+}$ can be introduced into the HT layer during the reconstruction process and the metallic species can be highly dispersed on the surface of $\mathrm{Mg}(\mathrm{Al}) \mathrm{O}$. The ball-flower-like $\mathrm{PtIn} / \mathrm{Mg}(\mathrm{Al}) \mathrm{O}$ catalyst exhibited high activity, excellent propene selectivity and superior durability as well as excellent resistance to the carbon deposition and Pt-sintering in the propane dehydrogenation to propene, which were mainly arising from its multi-level hierarchical microstructure with low specific surface area, and a large amount of strong and stable Pt-In interactions. It will be of great importance to revisit these catalysts and research the essential reasons for different catalytic performance in the PDH reaction by using more methods.

Supplementary Materials: The following are available online at http://www.mdpi.com/2073-4344/9/9/767/s1, Figure S1: Propane conversion and propene selectivity as function of time for blank tube, Figure S2: The selectivity of methane, ethane and ethene as function of time for different catalysts.

Author Contributions: J.L. wrote the manuscript, performed the experiments and analyzed data; M.Z. and Z.S. collected references and characterized the physico-chemical properties of materials; S.L. and J.W. made the figures and tables, collected and checked data; L.Z. provided research ideas, analyzed data and revised the manuscript.

Funding: This research was funded by the National Natural Science Foundation of China (21776214).

Acknowledgments: This work was supported by the National Natural Science Foundation of China (21776214) and State Key Laboratory of Chemical Resource Engineering.

Conflicts of Interest: The authors declare no conflict of interest.

\section{References}

1. Zhu, J.; Yang, M.L.; Yu, Y.; Zhu, Y.A.; Sui, Z.J.; Zhou, X.G.; Holmen, A.; Chen, D. Size-Dependent Reaction Mechanism and Kinetics for Propane Dehydrogenation over Pt Catalysts. ACS Catal. 2015, 5, 6310-6319. [CrossRef]

2. Xiong, H.; Lin, S.; Goetze, J.; Pletcher, P.; Guo, H.; Kovarik, L.; Artyushkova, K.; Weckhuysen, B.M.; Datye, A.K. Thermally Stable and Regenerable Platinum-Tin Clusters for Propane Dehydrogenation Prepared by Atom Trapping on Ceria. Angew. Chem. Int. Ed. 2017, 56, 8986-8991. [CrossRef] [PubMed]

3. Xia, K.; Lang, W.Z.; Li, P.P.; Yan, X.; Guo, Y.J. The properties and catalytic performance of PtIn/Mg(Al)O catalysts for the propane dehydrogenation reaction: Effects of $\mathrm{pH}$ value in preparing $\mathrm{Mg}(\mathrm{Al}) \mathrm{O}$ supports by the co-precipitation method. J. Catal. 2016, 338, 104-114. [CrossRef]

4. Cai, W.; Mu, R.; Zha, S.; Sun, G.; Chen, S.; Zhao, Z.J.; Li, H.; Tian, H.; Tang, Y.; Tao, F.; et al. Subsurface catalysis-mediated selectivity of dehydrogenation reaction. Sci. Adv. 2018, 4, eaar5418. [CrossRef] [PubMed]

5. Yu, C.; Ge, Q.; Xu, H.; Li, W. Effects of Ce addition on the Pt-Sn/gamma- $\mathrm{Al}_{2} \mathrm{O}_{3}$ catalyst for propane dehydrogenation to propylene. Appl. Catal. A 2006, 315, 58-67. [CrossRef]

6. Jung, J.W.; Kim, W.I.; Kim, J.R.; Oh, K.; Koh, H.L. Effect of Direct Reduction Treatment on Pt-Sn/Al $2 \mathrm{O}_{3}$ Catalyst for Propane Dehydrogenation. Catalysts 2019, 9, 446. [CrossRef]

7. Xia, K.; Lang, W.Z.; Li, P.P.; Yan, X.; Guo, Y.J. Analysis of the catalytic activity induction and deactivation of PtIn/Mg(Al)O catalysts for propane dehydrogenation reaction. RSC Adv. 2015, 5, 64689-64695. [CrossRef] 
8. Xia, K.; Lang, W.Z.; Li, P.P.; Long, L.L.; Yan, X.; Guo, Y.J. The influences of Mg/Al molar ratio on the properties of $\mathrm{PtIn} / \mathrm{Mg}(\mathrm{Al}) \mathrm{O}-\mathrm{x}$ catalysts for propane dehydrogenation reaction. Chem. Eng. J. 2016, 284, 1068-1079. [CrossRef]

9. Pham, H.N.; Sattler, J.J.H.B.; Weckhuysen, B.M.; Datye, A.K. Role of $\mathrm{Sn}$ in the Regeneration of $\mathrm{Pt} / \gamma-\mathrm{Al}_{2} \mathrm{O}_{3}$ Light Alkane Dehydrogenation Catalysts. ACS Catal. 2016, 6, 2257-2264. [CrossRef]

10. Zhu, Y.; An, Z.; Song, H.; Xiang, X.; Yan, W.; He, J. Lattice-Confined Sn (IV/II) Stabilizing Raft-Like Pt Clusters: High Selectivity and Durability in Propane Dehydrogenation. ACS Catal. 2017, 7, 6973-6978. [CrossRef]

11. Sun, P.; Siddiqi, G.; Vining, W.C.; Chi, M.; Bell, A.T. Novel Pt/Mg(In)(Al)O catalysts for ethane and propane dehydrogenation. J. Catal. 2011, 282, 165-174. [CrossRef]

12. Chen, M.; Xu, J.; Cao, Y.; He, H.Y.; Fan, K.N.; Zhuang, J.H. Dehydrogenation of propane over $\operatorname{In}_{2} \mathrm{O}_{3}-\mathrm{Al}_{2} \mathrm{O}_{3}$ mixed oxide in the presence of carbon dioxide. J. Catal. 2010, 272, 101-108. [CrossRef]

13. Redekop, E.A.; Galvita, V.V.; Poelman, H.; Bliznuk, V.; Detavernier, C.; Marin, G.B. Delivering a Modifying Element to Metal Nanoparticles via Support: Pt-Ga Alloying during the Reduction of $\mathrm{Pt} / \mathrm{Mg}(\mathrm{Al}, \mathrm{Ga}) \mathrm{O}_{\mathrm{x}}$ Catalysts and Its Effects on Propane Dehydrogenation. ACS Catal. 2014, 4, 1812-1824. [CrossRef]

14. Fang, S.; Zhang, K.; Wang, C.; Ma, L.; Zhang, Q.; Liu, Q.; Chen, L.; Chen, L.; Zhang, Q.; Tian, Z. The properties and catalytic performance of $\mathrm{PtSn} / \mathrm{Mg}(\mathrm{x}-\mathrm{Ga}) \mathrm{AlO}$ catalysts for ethane dehydrogenation. RSC Adv. 2017, 7, 22836-22844. [CrossRef]

15. Sun, G.; Zhao, Z.J.; Mu, R.; Zha, S.; Li, L.; Chen, S.; Zang, K.; Luo, J.; Li, Z.; Purdy, S.C.; et al. Breaking the scaling relationship via thermally stable $\mathrm{Pt} / \mathrm{Cu}$ single atom alloys for catalytic dehydrogenation. Nat. Commun. 2018, 9, 4454. [CrossRef] [PubMed]

16. Wegener, E.C.; Wu, Z.; Tseng, H.T.; Gallagher, J.R.; Ren, Y.; Diaz, R.E.; Ribeiro, F.H.; Miller, J.T. Structure and reactivity of Pt-In intermetallic alloy nanoparticles: Highly selective catalysts for ethane dehydrogenation. Catal. Today. 2018, 299, 146-153. [CrossRef]

17. Wang, T.; Jiang, F.; Liu, G.; Zeng, L.; Zhao, Z.J.; Gong, J.L. Effects of Ga doping on Pt/ $\mathrm{CeO}_{2}-\mathrm{Al}_{2} \mathrm{O}_{3}$ catalysts for propane dehydrogenation. AIChE J. 2016, 62, 4365-4376. [CrossRef]

18. Siddiqi, G.; Sun, P.; Galvita, V.; Bell, A.T. Catalyst performance of novel $\mathrm{Pt} / \mathrm{Mg}(\mathrm{Ga})(\mathrm{Al}) \mathrm{O}$ catalysts for alkane dehydrogenation. J. Catal. 2010, 274, 200-206. [CrossRef]

19. Liu, G.; Zeng, L.; Zhao, Z.J.; Tian, H.; Wu, T.; Gong, J.L. Platinum-Modified $\mathrm{ZnO} / \mathrm{Al}_{2} \mathrm{O}_{3}$ for Propane Dehydrogenation: Minimized Platinum Usage and Improved Catalytic Stability. ACS Catal. 2016, 6, 2158-2162. [CrossRef]

20. Del Angel, G.; Bonilla, A.; Peña, Y.; Navarrete, J.; Fierro, J.L.G.; Acosta, D.R. Effect of lanthanum on the catalytic properties of $\mathrm{PtSn} / \gamma-\mathrm{Al}_{2} \mathrm{O}_{3}$ bimetallic catalysts prepared by successive impregnation and controlled surface reaction. J. Catal. 2003, 219, 63-73. [CrossRef]

21. Jiang, F.; Zeng, L.; Li, S.; Liu, G.; Wang, S.; Gong, J.L. Propane Dehydrogenation over Pt/ $\mathrm{TiO}_{2}-\mathrm{Al}_{2} \mathrm{O}_{3}$ Catalysts. ACS Catal. 2015, 5, 438-447. [CrossRef]

22. De Miguel, S.R.; Jablonski, E.L.; Castro, A.A.; Scelza, O.A. Highly selective and stable multimetallic catalysts for propane dehydrogenation. J. Chem. Technol. Biotechnol. 2000, 75, 596-600. [CrossRef]

23. Zhang, Y.; Zhou, Y.; Qiu, A.; Wang, Y.; Xu, Y.; Wu, P. Propane dehydrogenation on PtSn/ZSM-5 catalyst: Effect of tin as a promoter. Catal. Commun. 2006, 7, 860-866. [CrossRef]

24. Shen, L.L.; Xia, K.; Lang, W.Z.; Chu, L.F.; Yan, X.; Guo, Y.J. The effects of calcination temperature of support on $\mathrm{PtIn} / \mathrm{Mg}(\mathrm{Al}) \mathrm{O}$ catalysts for propane dehydrogenation reaction. Chem. Eng. J. 2017, 324, 336-346. [CrossRef]

25. Nawaz, Z.; Tang, X.; Wang, Y.; Wei, F. Parametric Characterization and Influence of Tin on the Performance of Pt-Sn/SAPO-34 Catalyst for Selective Propane Dehydrogenation to Propylene. Ind. Eng. Chem. Res. 2010, 49, 1274-1280. [CrossRef]

26. Lin, L.; Yang, W.; Jia, J.; Xu, Z.; Zhang, T.; Fan, Y.; Kou, Y.; Shen, J. Surface structure and reaction performances of highly dispersed and supported bimetallic catalysts. Sci. China Ser. B Chem. 1999, 42, 571. [CrossRef]

27. Takehira, K.; Shishido, T. Preparation of supported metal catalysts starting from hydrotalcites as the precursors and their improvements by adopting "memory effect". Catal. Surv. Asia. 2007, 11, 1-30. [CrossRef]

28. Oladipo, A.A.; Ifebajo, A.O.; Gazi, M. Magnetic LDH-based $\mathrm{CoO}-\mathrm{NiFe}_{2} \mathrm{O}_{4}$ catalyst with enhanced performance and recyclability for efficient decolorization of azo dye via Fenton-like reactions. Appl. Catal. B 2019, 243, 243-252. [CrossRef] 
29. Belskaya, O.B.; Stepanova, L.N.; Gulyaeva, T.I.; Erenburg, S.B.; Trubina, S.V.; Kvashnina, K.; Nizovskii, A.I.; Kalinkin, A.V.; Zaikovskii, V.I.; Bukhtiyarov, V.I.; et al. Zinc influence on the formation and properties of $\mathrm{Pt} / \mathrm{Mg}(\mathrm{Zn}) \mathrm{AlO}_{\mathrm{x}}$ catalysts synthesized from layered hydroxides. J. Catal. 2016, 341, 13-23. [CrossRef]

30. Hibino, T.; Tsunashima, A. Characterization of Repeatedly Reconstructed Mg-Al Hydrotalcite-like Compounds: Gradual Segregation of Aluminum from the Structure. Chem. Mater. 1998, 10, 4055-4061. [CrossRef]

31. Wu, M.; Zhang, J.; Peng, Y.; Zhou, J.; Ruan, X.; Liu, J.; Liu, Q.; Xi, Y.; Frost, R.; Qian, G. An investigation into mechanism of cation adsorption by reconstruction of calcined layered double hydroxide. Microporous Mesoporous Mater. 2017, 242, 182-189. [CrossRef]

32. Yu, J.; Fan, G.; Yang, Y.; Li, F. Multi-level three-dimensional Mg-Al layered double hydroxide hierarchical microstructures with enhanced basic catalytic property. J. Colloid Interface Sci. 2014, 432, 1-9. [CrossRef] [PubMed]

33. Cavani, F.; Trifirò, F.; Vaccari, A. Hydrotalcite-type anionic clays: Preparation, properties and applications. Catal. Today 1991, 11, 173-301. [CrossRef]

34. Shannon, R.D. Revised effective ionic radii and systematic studies of interatomic distances in halides and chalcogenides. Acta Crystallogr. Sect. A 1976, 32, 751-767. [CrossRef]

35. Ma, X.; An, Z.; Zhu, Y.; Wang, W.; He, J. Pseudo-single-atom Platinum Induced by the Promoter Confined in Brucite-like Lattice for Catalytic Reforming. ChemCatChem 2016, 8, 1773-1777. [CrossRef]

36. Gao, Z.; Sasaki, K.; Qiu, X. Structural Memory Effect of Mg-Al and Zn-Al layered Double Hydroxides in the Presence of Different Natural Humic Acids: Process and Mechanism. Langmuir 2018, 34, 5386-5395. [CrossRef] [PubMed]

37. Zhang, Y.; Zhou, Y.; Wan, L.; Xue, M.; Duan, Y.; Liu, X. Synergistic effect between Sn and K promoters on supported platinum catalyst for isobutane dehydrogenation. J. Nat. Gas Chem. 2011, 20, 639-646. [CrossRef]

38. Im, J.; Choi, M. Physicochemical Stabilization of Pt against Sintering for a Dehydrogenation Catalyst with High Activity, Selectivity, and Durability. ACS Catal. 2016, 6, 2819-2826. [CrossRef]

39. Nagai, Y.; Hirabayashi, T.; Dohmae, K.; Takagi, N.; Minami, T.; Shinjoh, H.; Matsumoto, S.I. Sintering inhibition mechanism of platinum supported on ceria-based oxide and Pt-oxide-support interaction. J. Catal. 2006, 242, 103-109. [CrossRef] 